\title{
Christmas cards, Easter bunnies, and Granger-causality
}

\section{Journal Article}

Author(s):

Atukeren, Erdal

Publication date:

2008-12

Permanent link:

https://doi.org/10.3929/ethz-b-000069745

Rights / license:

In Copyright - Non-Commercial Use Permitted

Originally published in:

Quality \& Quantity 42(6), https://doi.org/10.1007/s11135-007-9078-2 


\title{
Christmas cards, Easter bunnies, and Granger-causality
}

\author{
Erdal Atukeren
}

Published online: 15 February 2007

(c) Springer Science + Business Media B.V. 2007

\begin{abstract}
This paper takes a closer look at the conceptual grounds of the notion of causality in Granger's sense. We start with the often jokingly made remark that 'Christmas card sales Granger-cause Christmas'. Then, we extend the example to the more challenging case of chocolate Easter bunny sales and Easter. We show that any references to Granger-causality in these cases are due to the misinterpretation of the concept. Moving further on methodological grounds, we argue that the concept of Granger-causality calls for a multivariate framework of analysis. This is because taking all available relevant information into account is indeed required in Granger's definition of causality. This is also in line with rational behaviour and learning under imperfect and incomplete information. The implications of employing a multivariate framework of analysis is discussed in terms of the additional insights it brings; namely, direct, indirect, and spurious cases of Granger-causality. Finally, we examine the semantics of the definition of causality in Granger's sense.
\end{abstract}

Keywords Semantics of Granger-causality - Granger-Hsiao direct causality · Econometric methodology

JEL Codes $\mathrm{B} 40 \cdot \mathrm{C} 50 \cdot \mathrm{A} 20$

\section{Introduction}

Granger's (1969) definition of causality and its extensions have become a standard tool of analysis in applied econometrics and time series analysis. According to Granger (1969), a (weakly stationary) stochastic variable X is said to cause another distinct (weakly stationary) stochastic variable $\mathrm{Y}$ if, in addition to all other available relevant

E. Atukeren

ETH Zurich, KOF-Swiss Institute for Business Cycle Research, WEH D4, Weinbergstrasse 35, Zürich, CH-8092 Switzerland

e-mail: atukeren@kof.ethz.ch 
information, the inclusion of the history of $\mathrm{X}$ significantly reduces the forecast error variance of Y. In econometric practice, whether X Granger-causes Y is usually tested by regressing $\mathrm{Y}$ on its own lags and on the lags of $\mathrm{X}$. If the lags of $\mathrm{X}$ are found to be jointly statistically significant, then, $\mathrm{X}$ is said to Granger-cause Y. Granger-causality from $\mathrm{Y}$ to $\mathrm{X}$ can be similarly defined.

The notion of causality in Granger's sense is an operational definition and it does not claim to have solved the question of causality in a philosophical sense (Granger 1980). In essence, Granger (1969) defines causality in terms of predictability and precedence. Nevertheless, the concept of Granger-causality is sometimes incorrectly referred to as if it is just "precedence with regularity", and the saying that "Christmas card sales Granger-cause Christmas' is given as a precautionary remark. Bishop (1979), Ahmed (1993), Dethier (1999), Kennedy (2003), Stiroh (2004), Dee (2005), Kreft and Sobel (2005) and Studenmund (2006), among others, mention this example. ${ }^{1}$ It would be an important drawback if the definition of causality in Granger's sense were so fragile given the large economics literature that employs Granger-causality tests.

In what follows, it is argued that the concept of Granger-causality survives this criticism. In addition, we examine the example of chocolate Easter bunny sales and Easter in terms of Granger-causality, which is a more challenging case than the Christmas example since the Easter date varies. Finally, based on the lessons from these examples, we elaborate on a number of conceptual, empirical, and semantic questions regarding the proper use of Granger-causality tests.

\section{Christmas card sales cannot be a Grange-cause of Christmas}

Let us look at the definition of Granger-causality given in the Introduction again. It can be said that there are three requirements for X to be a Granger-cause of Y.

(1) X and Y must be stochastic processes;

(2) X should precede Y;

(3) X should significantly contribute to the prediction of Y given all other available relevant information.

Applying condition (1), it follows that it is not even correct to mention the Christmas card sales and Christmas example in a discussion of Granger-causality since the calendar date of Christmas is not a stochastic event. As Drakopoulos and Torrance (1994: p.187) note, Granger's definition of causality '... excludes all non-stochastic variables'. Furthermore, since the Christmas date is perfectly known in advance, the date of Christmas will not be "predicted" better with the help of Christmas card sales figures. ${ }^{2}$ As a result, this example fails on requirements (1) and (3) above. Hence,

\footnotetext{
${ }^{1}$ See also Thurman and Fisher (1988) for a lively discussion of the chicken-egg problem in the context of Granger-causality tests.

2 Alternatively, Brittan (1998: p.85) gives the example that Christmas would still occur even if nobody sent Christmas cards. However, Granger (1980: p.350) is indeed careful to define his concept of causality in terms of predictability and not in terms of controllability, which is a stronger requirement. Still, what is meant by "significant" in Condition 3 remains as an open question. In the classical statistical sense, the term is associated with statistical significance while Bayesians interpret it differently; such as a higher likelihood for choosing the most probable model (e.g. in Gibbs sampling). See Thompson (1993: pp. 63-64) for a discussion on causality and significance testing. See also Atukeren (2005) for a Bayesian posterior odds ratio-based alternative to classical significance testing in the context of Granger-causality tests.
} 
Fig. 1 The Easter Sunday Date Index (ESDI), 1951-2006

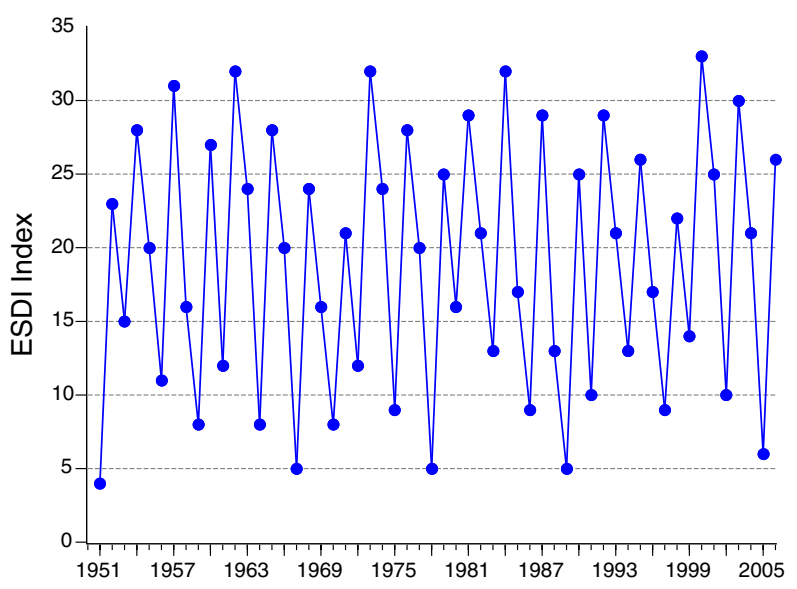

Christmas card sales cannot and do not Granger-cause Christmas. What remains is only a relationship showing precedence, but this is not a sufficient condition for Granger causality. ${ }^{3}$

\section{The Easter bunny challenge}

A more challenging and indeed an instructive example that provides food for thought is the relationship between chocolate Easter bunny sales and the actual Easter date. At least, the calendar date for Easter varies - albeit within a given interval in Spring. This provides some variation in the "dependent variable", which is lacking in the Christmas example. Then, an index series starting with the earliest possible date (March 22) and extending to the latest possible date (April 25) can be constructed. This provides an Easter Sunday date index (ESDI) series with values ranging between 1 and 35. To give our analysis a more realistic macroeconomic time series analysis flavour in terms of the number of observations, we use the values of ESDI starting from 1950s. Figure 1 displays the ESDI for the period 1951 - 2006 obtained for the Western Gregorian calendar.

Then, the question is whether Easter bunny sales might Granger-cause the Easter Sunday date index? In principle, the answer is no; because the calendar date of Easter (hence, the index) is not a stochastic event. It follows a rule, i.e., it is deterministic, and the condition (1) above is not satisfied. From a theoretical point of view, the concept of Granger-causality is again not applicable.

${ }^{3}$ In general, if $\mathrm{X}$ and $\mathrm{Y}$ are stochastic events, and even if $\mathrm{X}$ always precedes (strictly temporally prior to) Y, this does not automatically render X as a Granger-cause of Y. X should still be able to significantly contribute to the explanation of $\mathrm{Y}$ after taking any other available relevant information into account. In other words, the cause should contain unique information about the effect (Matthews 2005: p.20). The fact that Granger-causality is defined from a prediction aspect is also clear from the possibility of a feedback relationship between $\mathrm{X}$ and $\mathrm{Y}$, i.e. when not only X Granger-causes $\mathrm{Y}$ but also Y Granger-causes X. If causality in Granger's sense were defined only in terms of precedence or temporal ordering, then feedback would lead to a logically inconsistent (or challenging) proposition that $\mathrm{X}$ precedes $\mathrm{Y}$ and $\mathrm{Y}$ precedes $\mathrm{X}$ at the same time. But, as we discussed before, Granger's definition of causality is an operational one. Hence, the detection of a Granger-feedback relationship between $\mathrm{X}$ and $\mathrm{Y}$ implies that both $\mathrm{X}$ and $\mathrm{Y}$ contain unique information about each other. 
Fig. 2 Autocorrelation coefficients for the ESDI (20 lags)

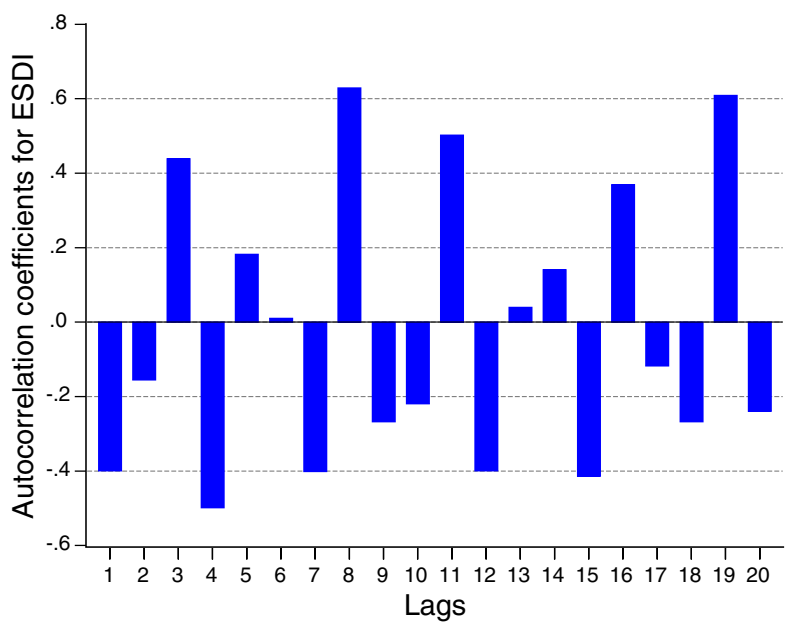

Now, let us assume that we still want to see if Granger-causality from an Easter Bunny sales series to the ESDI shown in Fig. 1 might possibly be detected purely on statistical grounds. To that aim, we first analyse the time series properties of the ESDI and test whether the series contains a unit root. Phillips-Perron and the KPSS tests indicate that the ESDI is stationary. (The empirical test results are available upon request.) Nevertheless, the visual analysis of the ESDI suggests the presence of (negative) autocorrelation, which appears as a certain regularity in the series. Therefore, we examine the sample autocorrelation function, taking a long view. Figure 2 shows the plot of the values of the autocorrelation function for ESDI up to 20 lags.

Given that even the autocorrelation between $\mathrm{ESDI}_{t}$ and $\mathrm{ESDI}_{t-19}$ is around 0.60 , one should indeed suspect that there is something special about the ESDI series. Nevertheless, we continue by fitting an autoregression of ESDI taking the first 20 lags into account. Note that generally a much lower order autoregressive (AR) representation is used for capturing the information contained in the history of the variables in question in testing for Granger-causality in a macroeconomic context. The estimation results from the AR(20) representation yield that about $93 \%$ of the variance in ESDI is explained. Figure 3 shows the residuals (actual - predicted) from this autoregression.

Now, a challenge arises. From a purely statistical point of view, there may exist an Easter bunny sales series containing natural fluctuations which may correlate well with the residual series displayed in Fig. 3. Whether such a series exists in reality or not, we use this example to illustrate the hypothetical possibility that Easter Bunny sales may be found to Granger-cause the ESDI if only a bivariate (and possibly misspecified) "model" is used. Nevertheless, when the condition (3) is applied, i.e. if "other available relevant information" is taken into account, Easter bunny sales would be found to contain no additional explanatory power in predicting the date of Easter and thus fail the requirement for Granger-causality. ${ }^{4}$ Note that a wider definition of

4 Another line of argument that Easter bunny sales cannot be a Granger-cause of the "Easter Sunday Date Index" is as follows. A deterministic process can be (virtually) forecastable from its own past. Hence, if the past is in the information set (as it should be in the Granger-causality test), another variable cannot provide additional information, failing the requirements for Granger-causality. In the Easter Sunday date example, if we extend the sample to (perhaps) 1,600's, use a much larger 
Fig. 3 Residuals from the AR(20) Representation of the ESDI

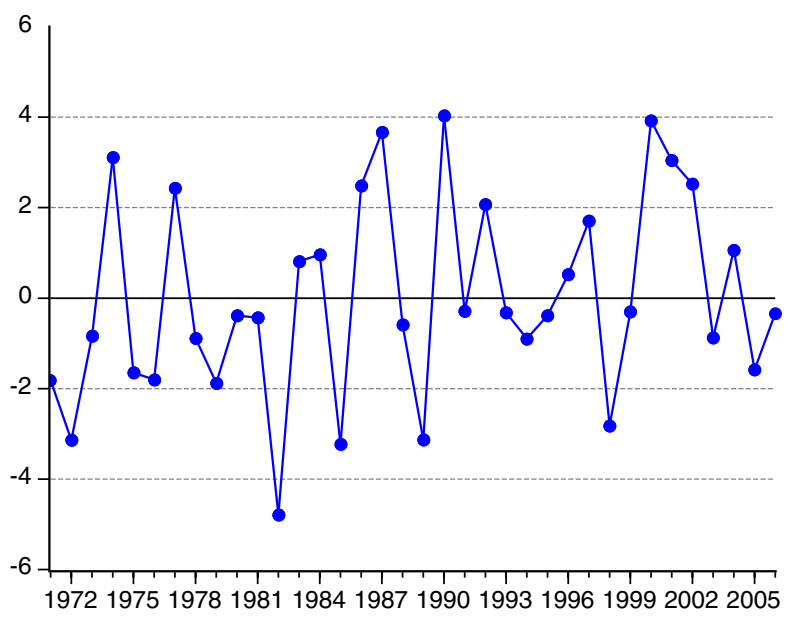

"available relevant information" is employed here - one that is not only restricted to omitted stochastic variables, but one that incorporates any other available relevant prior information. The additional information here would be a series showing the "Paschal Full Moon (PFM)" dates. Easter is the Sunday after the PFM. It is true that the PFM dates precede and also make it possible to "predict" the Easter Sunday date. However, the PFM cannot be considered as a "Granger-cause" of the Easter Sunday since it is not a stochastic series (the PFM dates are known until the year 4099). In general, the fact that any application (conceptual or empirical) involving Grangercausality first requires the series in question to be stochastic guards the concept from possible fallacies.

Next, let us consider whether there might be a Granger-causal relationship from Easter to Easter bunny sales. Except for an unlikely boycott on buying Easter bunnies or a general disruption in the production of Easter bunnies, it is natural to think that Easter causes Easter bunny sales. This is similar to the argument that Christmas causes Christmas card sales. Nevertheless, the relationship between Easter and Easter bunny sales is not one that falls into the domain of Granger-causality. First of all, condition (1) is not fulfilled. Second, Easter does not precede Easter bunny sales - except for the possible additional sales after Easter for a few days. Therefore, condition (2) is also not fulfilled.

Let us face more challenge. It is often argued that it is not Christmas (or Easter) but the anticipation of Christmas (Easter) that causes Christmas card (Easter bunny) sales. ${ }^{5}$ Is it then also possible that the anticipation of Christmas (Easter) "Grangercause" Christmas card (Easter bunny) sales? To answer that question, we would first need to answer how anticipations might be represented in this case. Since the Christmas or Easter date is perfectly known in advance, the anticipations "variable" cannot be represented in a probabilistic manner. A possible proxy for the anticipations in

Footnote 4 continued

AR order, and impose the restriction that the predicted date should be a Sunday, it is very unlikely that any other variable will be able to improve on this autoregression.

${ }^{5}$ Hoover (2001a: p.102) gives the example that '... money supply rises in late November and early December; it is a prima facie cause of Christmas sales; yet we do not think that the rising money supply genuinely causes Christmas sales'. 
this case might be to use an index showing the count down to the event date. As the event date approaches, sales increase. The relationship, however, need not be linear. For example, there may be more Christmas card sales up to a week before Christmas since people possibly write and send their cards early enough to allow for the delivery of the mail on time. Still, such an anticipations variable is not a stochastic process. That is, for a given day in December, one can only talk about the $x$ number of days remaining before Christmas, which is perfectly known in advance and $x$ is the same every year for that given day. The fact that the number of Christmas cards sold (on a given day) in December fluctuates from year to year has to do with other supply and demand related factors (such as demographics, preferences, technology, etc). That is, it is not because of changing anticipations on the likelihood of Christmas. Since the anticipation of a non-stochastic event (Christmas or Easter) is also non-stochastic, it cannot be said that the anticipation of Christmas (Easter) "Granger-causes" Christmas card (Easter bunny) sales. The concept of Granger-causality is not applicable to such cases in the first place.

\section{Further thoughts}

\subsection{Multivariate considerations}

The third condition for Granger-causality stated in Sect. 2 implies that claims of causal relationships between the variables of interest should be investigated in a multivariate framework. Granger (1988: p. 200) restates it alternatively as a requirement that ' $t$ ] he causal series contains special information about the series being caused that is not available in the other available series...'. This approach to testing for causal claims is conceptually important since it is also compatible with the assumption that rational economic agents use all available relevant information in making their decisions. As Moneta (2005: p. 442) argues '[i]ndeed, the rational expectation hypothesis ... involves the notion of Granger-causality, when it considers aggregate macroeconomic variables'.

A practical advantage of conducting Granger-causality tests in a multivariate framework is that the presence or absence of Granger-causal relationships between the variables of interest can be further analysed. For example Hsiao (1982) distinguishes between the notions of direct, indirect and spurious causality. According to Hsiao (1982), for a variable X to be direct Granger-cause of Y, X should Granger-cause Y in all settings: bi- and multi-variate. That is, the finding of Granger-causality should be invariant to the inclusion or exclusion of other variables. In other words, if $\mathrm{X}$ is a direct Granger-cause of Y, then this finding should remain robust regardless of what other factors (including structural breaks) affect the system $\mathrm{X}$ and $\mathrm{Y}$ belong to. From a methodological point of view, it can be argued that the concept of direct causality in Granger-Hsiao sense is related to the notion of stability (or 'faithfulness') defined in Pearl (2000) and Spirtes et al. (2000) and what Hoover (2001b) calls 'invariance under intervention'.

Let us further assume that in a trivariate framework (consisting of the stochastic variables $\mathrm{X}, \mathrm{Y}$ and $\mathrm{Z}$ ), $\mathrm{X}$ is not found to Granger-cause $\mathrm{Z}$ in their bivariate relationship. Let us also assume that $\mathrm{X}$ is found to be a direct Granger-cause of $\mathrm{Y}$, and $\mathrm{Y}$ is 
found to be a direct Granger-cause of Z. Then, assuming transitivity, Hsiao (1982) classifies $\mathrm{X}$ as an indirect Granger-cause of $\mathrm{Z}$ (i.e. $\mathrm{X} \rightarrow \mathrm{Y} \rightarrow \mathrm{Z}$ ) despite the absence of causality from $\mathrm{X}$ to $\mathrm{Z}$ in a bivariate model. ${ }^{6}$

We have seen in Sect. 3 that the possibility of detecting Granger-causality from Easter bunny sales to Easter on a purely statistical basis remains in a bivariate framework, i.e. when other relevant available information is not taken into account. This empirical challenge can now be addressed with the help of Hsiao's further refinement of the concept of Granger-causality. For example, it is clear that Easter bunny sales cannot be a direct Granger-cause of Easter since the third piece of information $(\mathrm{Z})$, i.e. the deterministic rule about the Easter date would make the Easter bunny sales variable redundant in a trivariate framework. Also, the sales of Easter bunnies cannot be an indirect Granger-cause of Easter since it cannot be a direct Granger-cause of the deterministic rule (the PFM date) for the Easter Sunday date. As a result, even if a Granger-causal relationship is found on a purely statistical basis between Easter bunny sales and the "Easter Sunday Date Index" in bivariate analysis, it would be discarded as a spurious one in a multivariate framework. ${ }^{7}$

An important implication of Hsiao's (1982) analysis is that the detection of Grangercausality in a bivariate framework is a necessary condition for direct causality, but it may well turn out to be spurious. Also, what is rejected when $\mathrm{X}$ is not found to Granger-cause Y in a bivariate model is only the hypothesis of direct Granger-causality. While this is an important implication in itself, it does not say anything about the possibility of indirect causal linkages. These arguments highlight the need for conducting the Granger-causality tests rather in a multivariate framework to allow for the detection of direct, indirect and spurious relationships. After all, taking all relevant information into account is in line with rational behaviour.

Nevertheless, extending the causal analysis into a multivariate framework is not without problems. First of all, it is subject to the constraint on the availability of information. Second, even if data are available, there are also degrees of freedom restrictions in estimation. Third, there are a number of methodological issues in the empirical implementation of Granger-causality tests, such as the selection of the optimum lag lengths in the test equations. Finally, a multivariate framework does not necessarily solve the problem of missing variables. As a result, any evidence for

6 In general, transitivity should be treated with caution in order to avoid a slippery slope argument. For instance, Hall (2004: p.4) gives the example: '[w] hat caused Socrates' death? Lots of things, perhaps - but not certainly his birth!', and suggests that '...in the final analysis, ... it is the utility of the concepts so produced that matters.' In this respect, the emphasis on use of all available "relevant" information in Granger's definition of causality helps restrict the possibility of slippery slope indirect causality. In addition, note that the condition for indirect causality is dependent on the presence of direct causality in the causal chain, which is a strong requirement, especially when the predictive aspect is considered.

7 Hsiao (1982) gives two definitions of spurious causality. First, let X, Y and Z be stochastic processes. Type I spurious Granger-causality arises when $\mathrm{X}$ is found to Granger-cause $\mathrm{Y}$ in a trivariate system of $\mathrm{X}, \mathrm{Y}$ and $\mathrm{Z}$; but not in a bivariate system of $\mathrm{X}$ and $\mathrm{Y}$. In this case, $\mathrm{X}$ is not a direct cause of $\mathrm{Y}$ since $\mathrm{X}$ does not Granger-cause $\mathrm{Y}$ in all systems. Also, if X does not Granger-cause Z directly and/or $\mathrm{Z}$ does not Granger-cause Y directly, then X is not an indirect Granger-cause of Y. Thus, the finding of causality from $\mathrm{X}$ to $\mathrm{Y}$ in the trivariate system is said to be spurious. The second (Type II) spurious Granger-causality result occurs when $\mathrm{Z}$ is a direct Granger-cause of both $\mathrm{X}$ and $\mathrm{Y}$. In the absence of $\mathrm{Z}$ (i.e. in a bivariate model of $\mathrm{X}$ and $\mathrm{Y}$ ), $\mathrm{X}$ may be found to Granger-cause $\mathrm{Y}$, capturing the missing common cause. (See also Lütkepohl 1982.). In this case, the initial Granger-causality finding should be discarded as spurious. 
Granger-causality (or lack thereof) should also be qualified as prima facie as Granger (1988: p.201) himself suggests.

\subsection{Some semantics}

Let us now examine the semantics of the third condition for Granger-causality stated in Sect. 2, i.e. using all other available relevant information. Here, we underline the qualifiers "all", "available" and "relevant", and consider their meaning in a deeper sense. In this respect, the qualifier "available information" should be interpreted as not only the availability of data on other variables, but also the availability of any other prior information which is not necessarily of stochastic nature. In the presence of incomplete/imperfect information, what one can rationally do at best is to use any other relevant information at one's disposal. In the context of Granger-causality tests, this suggests the use of a multivariate framework, possibly augmented by any other relevant prior information, as discussed earlier. ${ }^{8}$

The qualifier "relevant information" implies that some theoretical reasoning should be applied to the selection of possible candidate causes for the phenomena to be explained. In Granger's (1988: p. 201) own words '...possible causation is not considered for any arbitrarily selected group of variables, but only for variables for which the researcher has some prior belief that causation is, in some sense, likely.' Furthermore, what is embedded in "relevant information" is also a boundedly multivariate framework of analysis, where the relevancy criterion acts as a (rational) restriction on dimension of the system. In addition, "relevant information" should also be read in relation to the purpose of the analysis one intends to conduct. As such, the relevancy criterion also helps clarify the meaning of using "all available information". For example, it would not normally be relevant to include the number of sheep in a country in a study of the causal relationships between exports and economic growth. But, the information on sheep population becomes relevant if sheep and related products (wool, meat, etc.) are an important source of export revenues for the country in question. Still, the analysis should be conducted in a multivariate framework which includes some other factors / mechanisms contributing to economic growth. For example, it may be that (primary products) exports provide foreign exchange revenues, which in turn enable the imports of machinery and equipment, and thus help enhance the longterm economic growth potential in a country through capital accumulation. Note that, in line with the concept of Granger-causality, there is both "precedence" and "prediction" in this example: exports today may influence economic growth in the future.

\section{Conclusions}

This paper elaborates on the conceptual grounds of Granger-causality tests using two examples. The first one is the often jokingly given example that Christmas card sales Granger-cause Christmas, and the second one is the analogy (introduced in this paper) to chocolate Easter bunny sales and Easter. We argue that the concept of Grangercausality is not even applicable to these cases since Christmas and Easter are not stochastic events. Furthermore, we emphasise that for a stochastic variable $\mathrm{X}$ to be a

8 Indeed, Sargent's (1976) version of Granger's causality test involves the inclusion of dummy variables and other predetermined variables into the specification of the test equation. 
Granger-cause of another one (say, Y), X should significantly improve the prediction of $\mathrm{Y}$ after taking all available relevant information (including prior information) into account. Then, the knowledge of the date of Christmas or the knowledge of the rule for determining the Easter date would make the sales variables uninformative in "predicting" the Christmas or Easter date. Hence, the conditions for Granger-causality would not be satisfied. From an empirical point of view, what remains is a relationship of precedence; but that is not what Granger-causality is about. These points are worth pointing out since misinterpretations of Granger-causality exist in textbooks, journal articles and government and private sector research reports.

Furthermore, we provide a closer look into the premises of the notion of causality in Granger's sense. First, we argue that the concept of Granger-causality calls for a multivariate framework of analysis. Taking all available relevant information into account is indeed required in Granger's definition of causality. This is also in line with rational behaviour and learning under imperfect/ incomplete information. Second, a multivariate framework leads to new insights into the Granger-causal relationship among the variables of interest, such as direct, indirect, and spurious causality as Hsiao (1982) defines. Some of the inferences in favour of Granger-causality in a bivariate relationship may, for example turn out to be spurious in a multivariate context.

\section{Acknowledgements}

I would like thank Jochen Hartwig for inspiring discussions on the topic. His very helpful comments led to many improvements on an earlier version of this paper. The responsibility for any remaining errors, however, belongs entirely to me.

\section{References}

Ahmed S.: Does money affect output?, Bus. Rev. (Federal Reserve Bank of Philadelphia) July/August, 13-28 (1993)

Atukeren, E.: Measuring the strength of cointegration and granger-causality. Appl. Econ. 37, 1607$1614(2005)$

Bishop, R.V.: The Construction and use of causality tests. Agric. Econ. Res. 31, 1-6 (1979)

Brittan, S.: Causation in economic affairs. Hume Pap. Public Policy 6(4), 81-95 (1998)

Dee, P.: Quantitative modelling at the productivity commission, Productivity Commission (Australian Government), Melbourne. Accessed on March 15, 2006 at: http://www.pc.gov.au/research/consultancy/quantitativemodelling/quantitativemodelling.pdf (2005)

Dethier, J-J.: Governance and economic performance: A survey, discussion papers on development policy, No. 5, Center for Development Research (ZEF), Bonn, Germany (1999)

Drakopoulos, S.A., Torrance, T.S.: Causality and determinism in economics. Scott. J. Polit. Econ, 41(2), 176-193 (1994)

Granger, C.W.J.: Investigating causal relations by econometric models and cross-spectral methods. Econometrica 37, 424-428 (1969)

Granger, C.W.J.: Testing for causality: a personal view point. J. Econ. Dyn. Control. 2, 329-352 (1980)

Granger, C.W.J.: Some recent developments in a concept of causality. J. Econ. 39, 199-211 (1988)

Hall, N.: Philosophy of causation: blind alleys exposed; promising directions highlighted. Philos. Compass. 1(2), 1-9 (2004)

Hoover, K.D.: The Methodology of empirical macroeconomics. Cambridge University Press, Cambridge UK (2001a)

Hoover, K.D.: Causality in macroeconomics. Cambridge University Press, Cambridge U.K (2001b)

Hsiao, C.: Autoregressive modelling and causal ordering of economic variables. J. Econo. Dyn. Control. 4, 243-259 (1982)

Kennedy, P. : A Practical guide to econometrics. Blackwell Publishing Ltd, Oxford UK (2003) 
Kreft, S.F., Sobel R., S.: Public policy, entrepreneurship, and economic freedom. Cato J. 25(3), 595$616(2005)$

Lütkepohl, H.: Non-causality due to omitted variables. J. Econometrics 19(2/3), 367-378 (1982)

Matthews P.H.: Paradise lost and found? the econometric contributions of clive W.J. Granger and Robert F. Engle, Rev. Polit. Econ. 17(1), 1-28 (2005)

Moneta, A.: Causality in macroeconomics: Some considerations about reductionism and realism. J. Econ. Methodol. 12(3), 433-253 (2005)

Pearl, J.: Causality: Models, reasoning, and inference. Cambridge University Press, Cambridge UK (2000)

Sargent, T.J.: A classical macroeconometric model for the United States. J. Polit. Econ. 84, 207237 (1976)

Sprites, P., Glymour, C., Scheines, R.: Causation, prediction, and search. 2nd edn. The MIT Press, Cambridge MA (2000)

Stiroh, L.: Proving causation in damage analyses, Antitrust insights (National Economic research associates - NERA), March/April, 1-7. Accessed on March 15, 2006 at http://www.nera.com/ NewsletterIssue/AT\%20Insights_Mar-Apr\%202004.pdf (2004)

Studenmund, A.H. : Using econometrics: A practical guide,. Pearson, Boston (2006)

Thompson, G.F.: Causality in economics: rhetorical ethic or positivist empiric?. Qual. Quant. 27, 47$71(1993)$

Thurman, W.N., Fisher, M.E.: Chickens, eggs, and causality, or which came first. Am. J. Agric. Econ. 70(2), 237-238 (1988) 